\title{
DETECTABILIDADE MAGNÉTICA DE DIQUES DO ARCO DE PONTA GROSSA: UM ESTUDO INTEGRADO DE MAGNETOMETRIA TERRESTRE/AÉREA E MAGNETISMO DE ROCHA
}

\author{
NAOMI USSAMI*, ALEXANDRE KOLISNYK*, MARIA I.B. RAPOSO*, FRANCISCO J.F. FERREIRA**, \\ EDER C. MOLINA* e MÁRCIA ERNESTO*
}

\begin{abstract}
ON THE MAGNETIC DETECTABILITY OF PONTA GROSSA DYKE SWARMS: AN INTEGRATED GROUND/AIRBONE MAGNETOMETRY AND ROCK MAGNETISM STUDY. Mesozoic Ponta Grossa Arch Dyke Swarms occur between the eastern border of the Paraná basin and the southeastern Brazilian continental margin. It comprises of a few to a hundred meters-thick tholeiitic dykes which intrude the Precambrian basement and Paleozoic sediments preferably along the NW direction. Preliminary analysis of aeromagnetic data suggested that these dykes may extend northwesterly towards the center of the Paraná basin, under basaltic flows and post-volcanic sediments. In order to investigate the detectability of these non-exposed dykes by conventional airborne magnetometry, a combined study of ground/airborne magnetometry and dyke magnetism was carried out in the northern part of the Ponta Grossa Arch (Fartura city, SP) where dykes are exposed. A total component ground magnetic profile of $16 \mathrm{~km}$ in length was set up with an average spacing of 12.5 to $25 \mathrm{~m}$ between readings. There is clear correspondence between exposed dykes and short-wavelength magnetic anomalies. The ground magnetic data were transformed into aeromagnetic data by the upward continuation technique at different heights until it coincided with the altitude of one flight-line of the aeromagnetic survey flown at 450 meters above ground level (a.g.l.). This process reveals that most of dyke-generated magnetic anomalies are highly attenuated at altitude as low as $100 \mathrm{~m}$ a.g.L At 450 $\mathrm{m}$, only anomalies associated with a group of closed spaced dykes or high-amplitude (above 4,000 nT on üíe ground) magnetic anomaly of a single dyke remain. These results were integrated with data of magnetization of dyke samples in order to establish a quantitative criteria of dykes detectability by conventional airborne magnetometry. For this particular region, it is found that most of the dykes can only be detected by ground magnetic survey due to low magnetization and small thickness of the dykes. Two additional ground magnetic profiles were set up in the interior of the Paraná basin, where dykes are not exposed and the results analysed. They indicate that the Ponta Grossa Arch dykes may extend northwesterly towards the center of the basin, cutting the thick pile of lava flows. This finding reinforces the geochemical and paleomagnetic evidence that the Ponta Grossa dyke swarms are associated with a late stage or a subsequent tectonomagmatic event following the main Serra Geral flood basalt volcanism in the southern and central Paraná basin.
\end{abstract}

Keywords: Dyke magnetism, dyke detectability, aeromagnetic surveys

RESUMO Enxames de diques mesozóicos ocorrem no Arco de Ponta Grossa, entre a borda leste da Bacia do Paraná e a margem continental sudeste do Brasil. Estes enxames compreendem diques, na maioria toleíticos, com larguras que variam de alguns metros a $100 \mathrm{~m}$, e intrudem o embasamento Pré-Cambriano e os sedimentos paleozóicos na direção preferencial NW. A análise preliminar dos dados aeromagnéticos sugeriu que os diques continuam na direção noroeste, em direção ao centro da Bacia do Paraná, sob os derrames basálticos e sedimentos pósvulcânicos. Com o objetivo de investigar a detectabilidade magnética de diques não-aflorantes por aerolevantamentos convencionais, um estudo combinado de magnetometria terrestre/aérea e magnetismo de rochas foi conduzido na região norte do Arco de Ponta Grossa (Fartura, SP), onde os diques afloram. Um perfil magnetométrico terrestre de $16 \mathrm{~km}$ de extensão, com intervalos entre as medidas de 12,5 a $25,0 \mathrm{~m}$, foi levantado na região. Existe uma correspondência entre os diques aflorantes e anomalias magnéticas de curto comprimento de onda. Os dados magnetométricos terrestres foram transformados em dados aeromagnéticos pela técnica de continuação para cima, a várias alturas, até coincidir com a linha de vôo de um aerolevantamento efetuado a $450 \mathrm{~m}$ acima do terreno (a.t.). Este processo revelou que a maioria das anomalias magnéticas de diques são fortemente atenuadas a uma altura de apenas $100 \mathrm{~m}$. A $450 \mathrm{~m}$ a.t, somente anomalias associadas a um grupo de diques ou anomalia devida a um único dique com forte magnetização permanecem. Estes resultados foram integrados aos dados de magnetização dos diques medidos em laboratório, a fim de estabelecer um critério quantitativo de detectabilidade magnética de diques a partir de aerolevantamentos magnéticos con-vencionais. Conclui-se que, nesta região, a maioria dos diques somente são detectados por levantamentos terrestres, por causa da baixa magnetização e pequena largura dos diques. Dois perfis magnetométricos terrestres adicionais foram levantados na região de Maringá (PR) e Teodoro Sampaio (SP), onde os diques não afloram, e os resultados analisados. Estes mostram que os diques do Arco de Ponta Grossa devem continuar para noroeste, em direção ao eixo central da bacia, cortando discordantemente as espessas seqüências de derrames basálticos. Estes resultados reforçam as evidências geoquímica e paleomagnética de que os diques da borda leste da Bacia do Paraná estão associados a um evento tectonomagmático tardio ou subseqüente ao derrame basáltico principal da Formação Serra Geral das partes sul e central da Bacia do Paraná.

Palavras-chaves: Magnetismo de diques, detectabilidade de diques, levantamentos aeromagnéticos

INTRODUÇÃO Aerolevantamentos magnéticos são utilizados em mapeamentos de corpos intrusivos, em especial os diques de diabásio, que geralmente apresentam magnetização maior que a rocha encaixante. Entretanto, enxames de diques são freqüentemente encontrados associados a falhas e fraturas, através das quais o magma chega à superfície. Tais feições estruturais são também importantes fontes de anomalias magnéticas. Portanto, a utilização de dados aeromagnéticos na detecção de diques em regiões onde estes encontram-se cobertos por vegetação, solo, sedimentos ou derrames vulcânicos

\footnotetext{
* Departamento de Geofísica, Instituto Astronômico e Geofísico, Universidade de São Paulo, Caixa Postal 9638, CEP 01065, São Paulo, SP, Brasil ** Pós-graduando do Instituto de Geociências, Universidade de São Paulo, Caixa Postal 20899, CEP 01498, São Paulo, SP, Brasil
} 
pressupõe o estabelecimento de critérios quantitativos de detectabilidade de corpos de diferentes magnetizações, dimensões e profundidades (Schwarz et al. 1987).

O Brasil possui grande parte de seu território continental coberto por dados aeromagnéticos (DNPM 1984). A possibilidade de utilização desses levantamentos na detecção de enxames de diques traria uma grande contribuição aos trabalhos de mapeamento e amostragem desses corpos, notadamente em áreas onde os diques não se encontram totalmente aflorantes. Por exemplo, os dados aeromagnéticos da parte leste da bacia do Paraná revelaram importantes feições estruturais e magnéticas de direção NW, associadas ao Arco de Ponta Grossa (Ferreira 1982a, b, Fúlfaro et al 1982). A partir desses mesmos dados, foi proposta a continuidade do enxame de diques aflorantes no Arco de Ponta Grossa para o interior da bacia, sob os derrames vulcânicos da Formação Serra Geral e sedimentos do Cretáceo Superior do Grupo Bauru.

A fim de melhor compreender a ocorrência de enxames de diques no interior da bacia do Paraná, bem como fornecer uma contribuição ao problema de utilização de dados aeromagnéticos convencionais na detecção e mapeamento de diques básicos dentro do território brasileiro, foi iniciado um estudo combinado de magnetometria terrestre e magnetização de rochas na região norte do Arco de Ponta Grossa, onde diques são aflorantes. $\mathrm{O}$ objetivo deste estudo é apresentar um critério quantitativo de detectabilidade de corpos magnetizados, levando em conta características do aerolevantamento e propriedades físicas, como magnetização e largura dos diques.

Este estudo mostra que somente por meio de magnetometria terrestre é possível inferir a freqüência de ocorrência de diques. É sugerida também uma relação estrutural e estratigráfica entre os diques do Arco de Ponta Grossa e os derrames da Formação Serra Geral do interior da Bacia do Paraná.

ÁREA DE ESTUDO O mais importante enxame de diques do Cretáceo Inferior, no Brasil, ocorre no Arco de Ponta Grossa (Fig. 1). São milhares de diques, alinhados principalmente segundo a direção N40-45W, concordantes com os maiores lineamentos tectônicos do embasamento. A maior parte deles ocorre entre os lineamentos São JerônimoCuriúva e Rio Alonzo e suas larguras variam de alguns metros até algumas centenas de metros e extensão entre 1 e 50 km (Fúlfàro \&Suguio 1967, Fúlfaro \&Suguio 1974,Fúlfaro et al 1982).

Segundo Piccirillo et al (1988a), os diques apresentam alto valor de $\mathrm{TiO}_{2}$, similares em composição aos derrames basálticos da região norte (acima do lineamentp do Rio Piquiri) da Bacia do Paraná. As intrusões de diques, na sua maioria basaltos toleíticos e ácidos (riodacitos), ocorrem tanto no embasamento cristalino como nos sedimentos paleozóicos. Estudos paleomagnéticos (Ernesto \& Pacca 1988, Raposo \& Ernesto 1989) indicam que o magmatismo que resultou nas rochas intrusivas da região nordeste da bacia (sills) e nos diques do Arco de Ponta Grossa é mais recente que os derrames da parte sul (sul do lineamento do Rio Uruguai) e central (entre os lineamentos do Rio Uruguai e Piquiri) da bacia.

A área deste estudo situa-se na parte norte do Arco de Ponta Grossa (Fig. 1), entre as cidades de Sarutaiá e Fartura, no sudeste do Estado de São Paulo (Fig. 2), e nas proximidades do Lineamento Guapiara (Ferreira 1982a,b, Fúlfàro et al 1982) que se estende para o interior da Bacia do Paraná. Os diques aflorantes na região de Fartura cortam os sedimentos paleozóicos de idade permiana até juro-cretácica e são mais numerosos

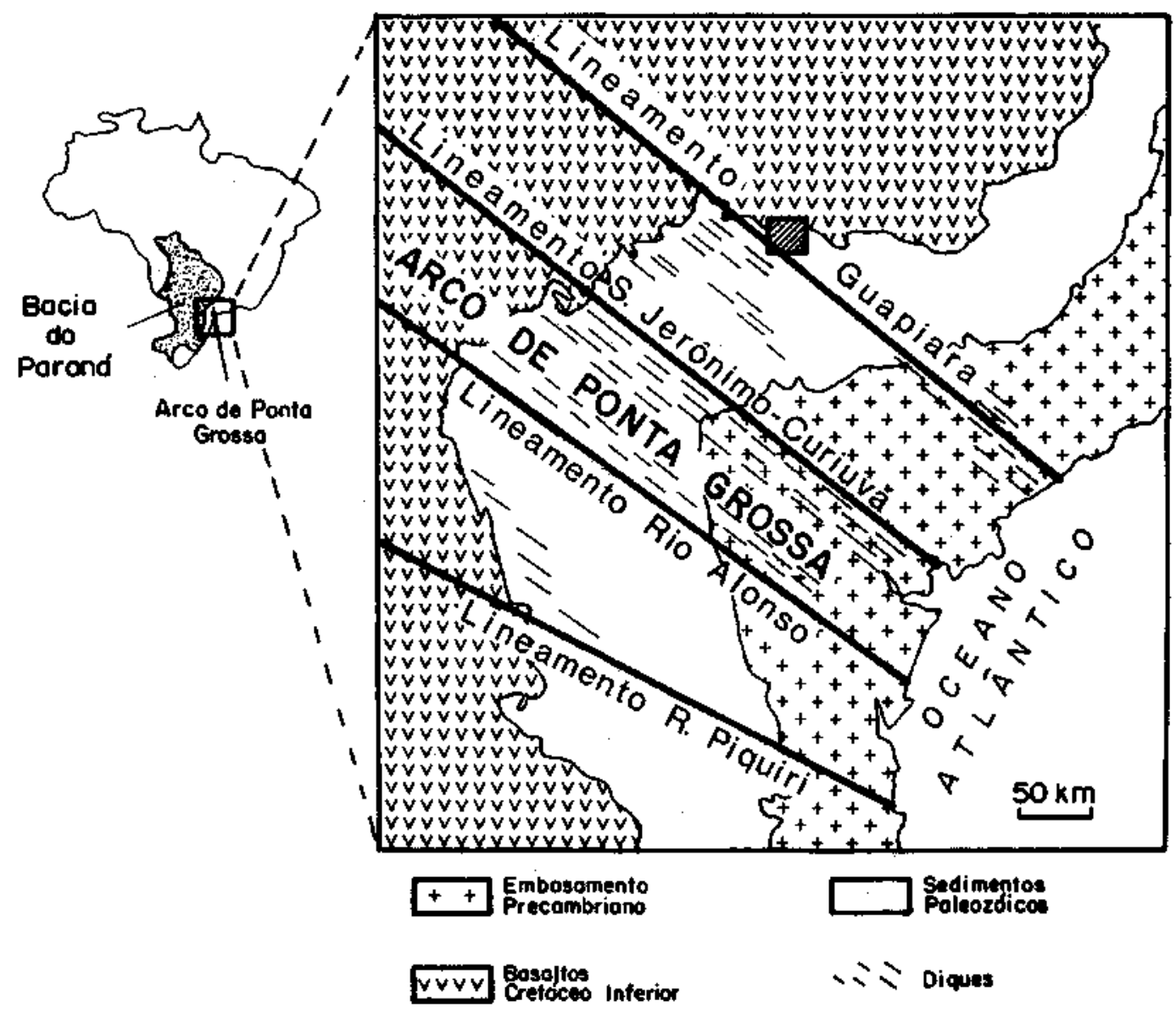

Figura 1 - Mapa regional do Arco de Ponta Grossa com a localização da área de estudo, indicada com um quadrado hachurado Figure 1 - Regional map of Ponta Grossa Arch with study area within the hachured square 
(Fig. 2) nas áreas de afloramento dos sedimentos da Formação Corumbataí do Permiano Superior (Zaine 1980).

\section{MAGNETOMETRIA TERRESTRE Coleta de dados}

O perfil de magnetometria terrestre, com comprimento de $16 \mathrm{~km}$, está situado entre as cidades de Sarutaiá e Fartura (Fig. 2). A escolha deste perfil foi determinada pelos seguintes critérios:

cruzamento com a direção dos diques com ângulo mínimo de $45^{\circ}$;

orientação da linha terrestre concordante com uma linha de vôo do aerolevantamento Projeto Botucatu (Paulipetro 1982)

estrada de fácil acesso, com bons afloramentos de diques e desprovida de fontes de perturbações magnéticas como fios de alta tensão, fios elétricos e cercas de arame.

O levantamento foi efetuado em dois dias de campo, com três leituras em cada ponto, espaçados de $12,5 \mathrm{~m}$ em regiões de forte gradiente horizontal do campo, geralmente associado à presença de diques, e 25 e $50 \mathrm{~m}$ em locais de médio e baixo gradiente horizontal do campo, respectivamente.

As medidas da componente total do campo geomagnético foram efetuadas com dois magnetômetros de precessão de próton, cuja sensibilidade é de $1 \mathrm{nT}\left(10^{-9}\right.$ Tesla). Foram obtidas aproximadamente 360 medidas ao longo do perfil. Na figura 2 , são mostrados os locais de amostragem dos diques que tiveram a rnagnetização remanescente natural e a susceptibilidade magnética determinadas em laboratório, bem como os diques aflorantes mas não amostrados devido ao alto grau de alteração das rochas.
Remoção das variações temporais do campo geomagnético A monitoração da variação diurna do campo geo-magnético foi efetuada numa base fixa onde cinco leituras eram feitas a cada 15 minutos. Os dados referentes aos dois dias de monitoração são mostrados na figura 3. As duas bases situam-se em lugares diferentes, o que explica a diferença nos valores absolutos medidos. No gráfico dos dados da base do dia 18 de dezembro interrompeu-se a monitoração do campo entre 12 e 16 horas.

A remoção da variação temporal do campo foi efetuada subtraindo-se as variações do campo na base referidas a um campo de referência. Para a base do dia 17/12, o valor do campo de referência foi de $23.455 \mathrm{nT}$ e, no dia $18 / 12$, o valor foi de $23.500 \mathrm{nT}$, correspondentes à primeira leitura na base que coincidiu com o início das medidas ao longo do perfil. Efetuou-se uma interpelação linear entre cada leitura a fim de obter a correção nestes intervalos. Os valores da componente total do campo ao longo do perfil, após a remoção das variações temporais, são mostrados na figura 4.

Remoção da componente regional Por se tratar de uma perfil local, um ajuste linear por mínimos quadrados é suficiente para remover o campo regional. A equação 1 descreve o campo regional em nanoTesla e este é mostrado com uma linha contínua na figura 4.

\subsection{6,0 - 8,4 x distância (em km)}

O resultado da remoção deste campo é mostrado na figura 5 , juntamente com a localização dos principais diques aflorantes.

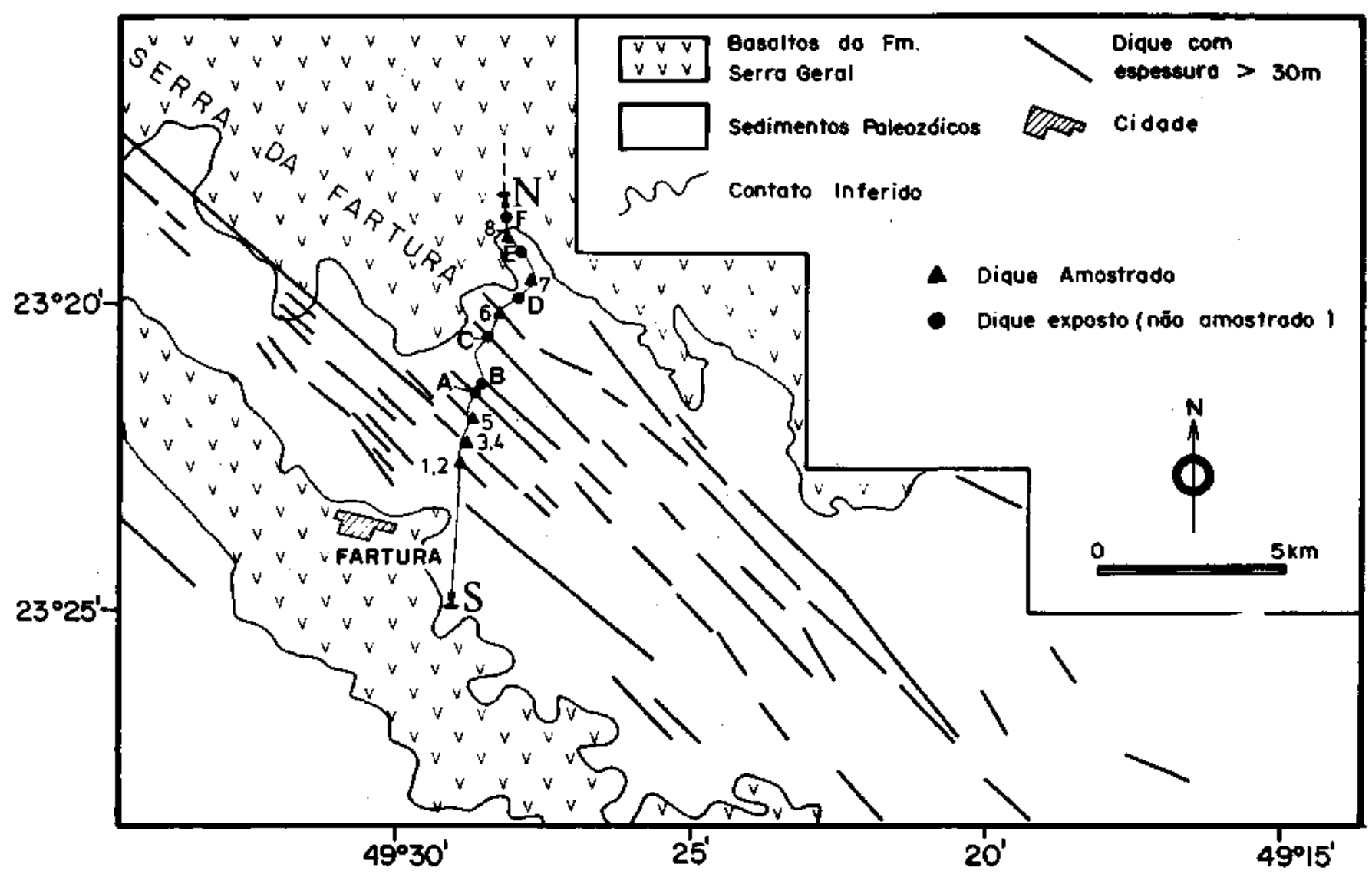

Figura 2 - Mapa geológico simplificado da região de Fartura, modificado de Zaine (1980). Os números indicam os sítios onde foram amostrados os diques que tiveram a rnagnetização determinada em laboratório. As letras indicam os diques observados mas não amostrados

Figure 2 - Simplified geological map of Fartura city region modified from Zaine (1980). The numbers indicate the sites of sampled dykes whose magnetic properties were measured in laboratory. The letters indicate observed unsampled dykes 


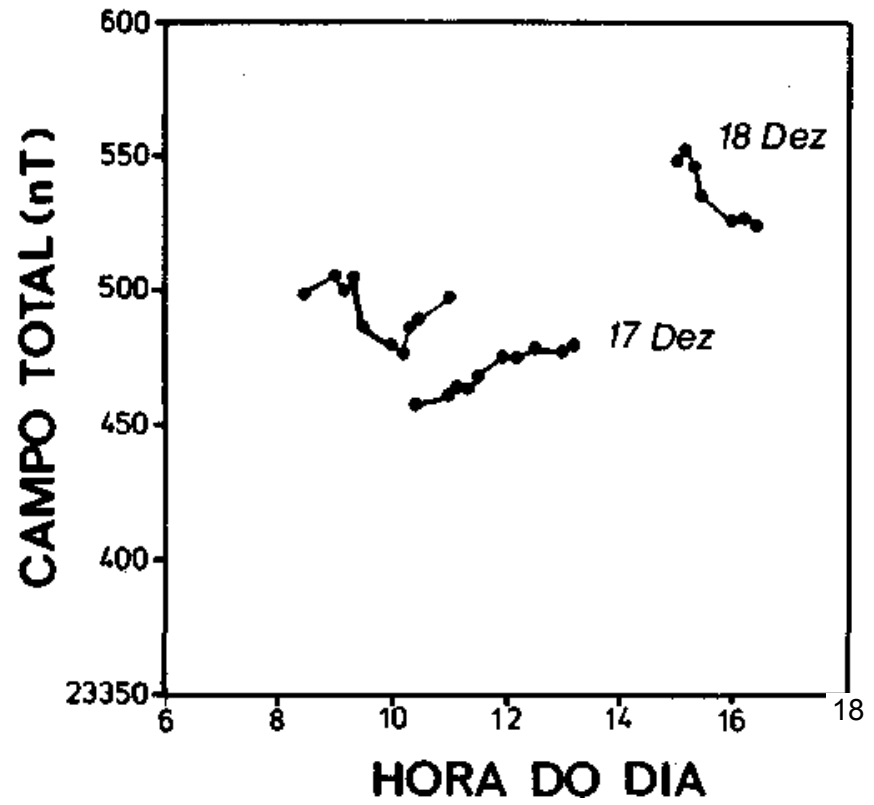

Figura 3 - Dados da base de monitoração das variações diurnas do campo geomagnético.

Figure 3 - Daily variation of the geomagnetic field measured at the base station.

Anomalias magnéticas de diques No perfil da figura 5, estão localizados os diques, amostrados e não amostrados, bem como os diques inferidos a partir do padrão de anomalia magnética característica de dique.
A anomalia magnética de um dique isolado, cuja magnetização é maior que a da rocha encaixante, apresenta-se negativa a sul e positiva a norte, se a magnetizacão total (natural mais induzida) se aproxima da magnetizacão induzida em corpos situados na latitude magnética sul. Onde a anomalia magnética está claramente associada a um dique aflorante, observa-se o padrão magnético de dique, doravante referido como p.m.d. (por exemplo, o dique $n^{\circ} 6$ da Fig. 5). Anomalias com p.m.d., mas não diretamente associáveis a diques aflorantes, são provavelmente causadas por diques encobertos. Anomalias com diferentes comprimentos de onda, mas que não apresentam o p.m.d., estão associados a sills e/ou feições do embasamento cristalino como falhas e fraturas.

Observa-se que, em média, a amplitude pico a pico das anomalias não excede $1.000 \mathrm{nT}$, com exceção dos diques localizados nas extremidades do perfil. São eles, os diques não aflorantes $(\mathrm{C}$ e $\mathrm{D})$ e o dique aflorante amostrado número 6 que apresenta amplitude pico a pico de $6.000 \mathrm{nT}$.

DADOS TERRESTRES X AEROLEVANTAMENTO A magnetometria terrestre permite que as anomalias magnéticas possam ser melhor vinculadas às suas fontes. Neste estudo, as principais fontes de anomalias magnéticas são os diques de diabásio e falhas ou fraturas do embasamento. O procedimento seguinte foi transformar as anomalias magnéticas medidas na superfície em anomalias que seriam observadas a diferentes altitudes, como no aerolevantamento, por meio de técnica numérica de transformação de campo potencial denominada continuação para cima. Desta forma, podemos inferir as fontes magnetizadas que efetivamente são detectadas no aerolevantamento.

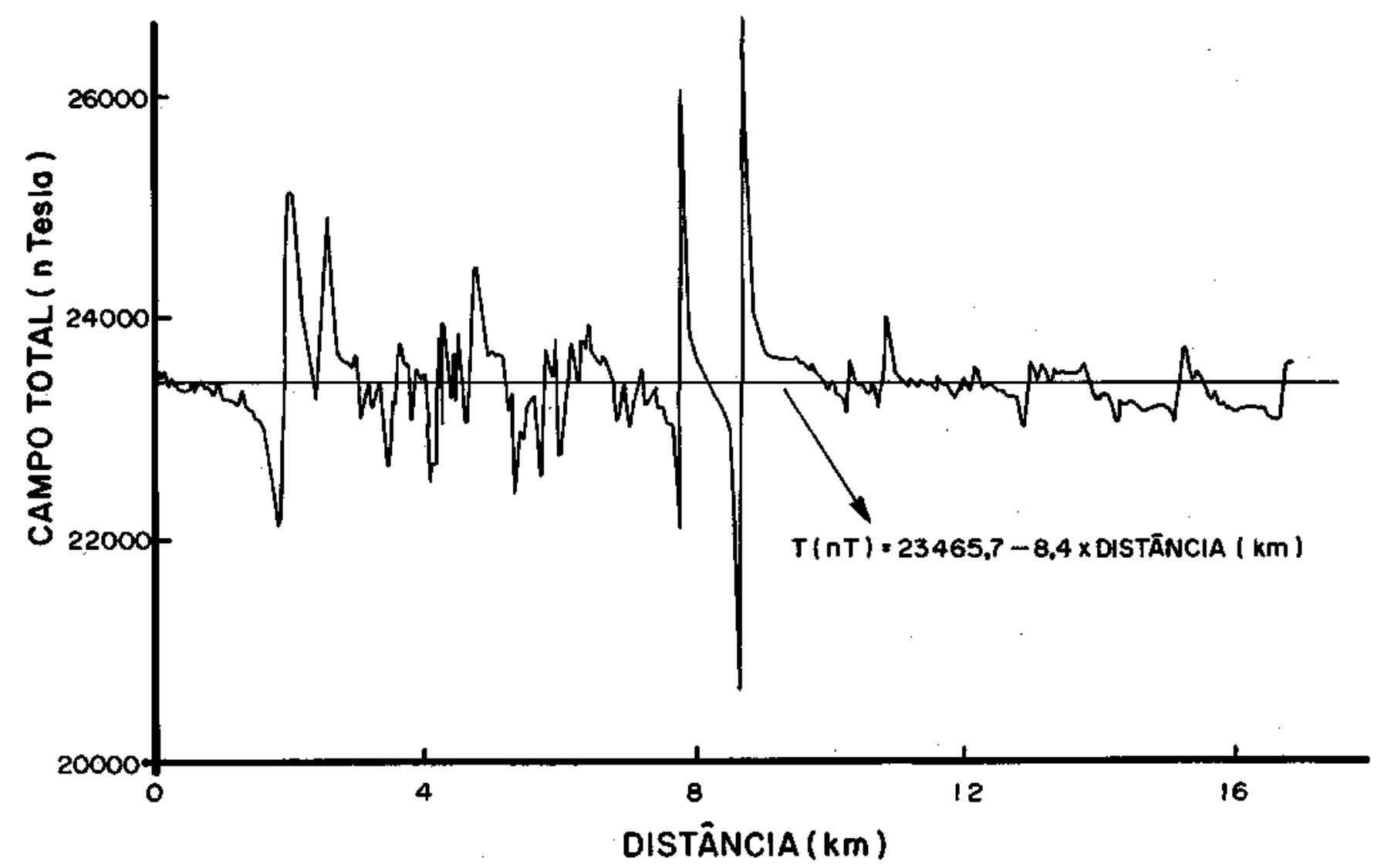

Figura 4 - Perfil magnetométrico terrestre (componente total do campo) entre Sarutaiá e Fartura. A reta indica o ajuste linear por minimos quadrados que corresponde ao campo regional

Figure 4 - Ground magnetometry (total field) between Sarutaiá and Fartura cities. The straight line is the least-squares fit for the regional field 


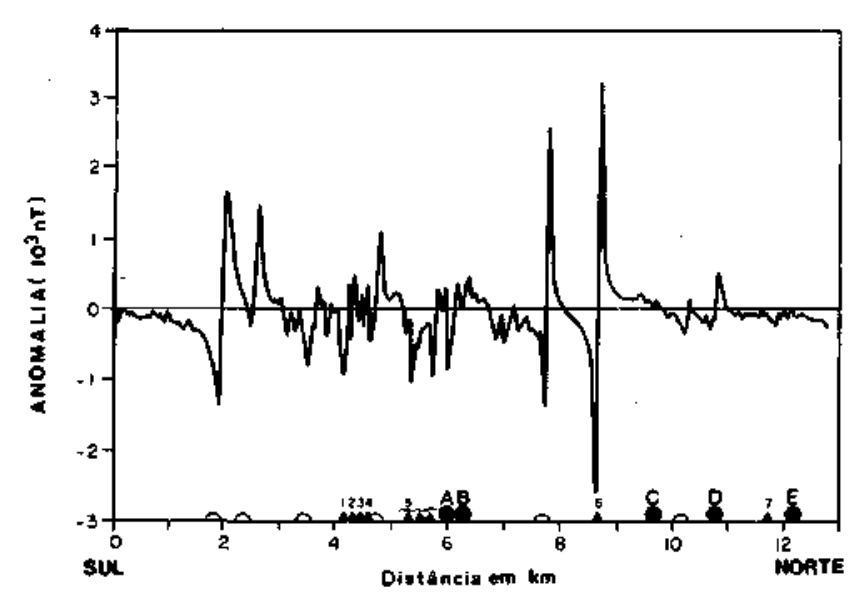

Figura 5 - Anomalias magnéticas residuais resultantes da remoção do campo regional, juntamente com a localização dos diques observados e amostrados (triângulo), observados mas não amostrados (círculo cheio) e inferidos (semi-círculo aberto)

Figure 5 - Residual magnetic anomaly profile after removal of regional field together with the sites of sampled (triangles), observed and unsampled (full circles) and inferred (open semi-circle) dykes

Continuação para cima dos dados terrestres Existem diversas técnicas numéricas para se efetuar a continuação de campos potenciais, sendo que a mais simples faz uso da transformada rápida de Fourier (Baranov 1975, Kanasevich 1981). A continuação para cima é efetuada no domínio do número de ondas e consiste, no caso unidimensional, em multiplicar os coeficientes de Fourier do campo magnético medido na superficie pelo fator exp(-z K) no qual $z$ é a altura de continuação e K é o número de onda definido como $2 \pi \lambda(\lambda=$ comprimento de onda). $\mathrm{O}$ campo magnético continuado no dominio espacial é obtido pela transformada inversa de Fourier dos coeficientes continuados no domínio do número de ondas.

Esta técnica requer que os dados estejam igualmente espaçados. Neste caso, o espaçamento entre as medidas era irregular e foi regularizado com um ajuste por uma função spline e reamostrado com espaçamento de $25 \mathrm{~m}$.

Na figura 6 são mostrados os perfis magnetométricos terrestre (Fig. 6a) e continuado para cima nas alturas de $100 \mathrm{~m}$ (Fig. 6b) e 200 m (Fig. 6c). E mantida a mesma escala nos três gráficos para realçar o efeito da atenuação do sinal magnético em alturas cada vez maiores. O fator de atenuação para anomalias de curto comprimento de onda, como aquelas associadas aos diques, é de aproximadamente sete para altitude de $100 \mathrm{~m}$ acima do terreno.

Dados do aerolevantamento $O$ perfil magnetométrico terrestre coincide aproximadamente com uma linha de vôo do aerolevantamento denominado Projeto Botucatu. A partir deste aerolevantamento foram elaboradas cartas aeromagnéticas em escala 1:50.000 (Paulipetro 1982, Ferreira 1982b).

Na figura $7 \mathrm{a}$, é mostrado o mapa de contorno referente à área deste estudo, com intervalo de contorno de 20 nT. Este mapa foi obtido seguindo os mesmos procedimentos da companhia executora do levantamento, ou seja, a grade que gerou os contornos tem resolução de $1 \mathrm{~km} \times 1 \mathrm{~km}$. As linhas de vôo (pontilhado) bem como a localizacão do perfil terrestre entre Sarutaiá e Fartura (linha contínua) são mostradas na mesma figura. Os mapas de contorno magnético do projeto Botucatu, em escala 1:50.000, apresentam curvas de contorno em intervalos de $5 \mathrm{nT}$. Desta forma, a área retangular delimitada na figura 7 a foi re-contornada em intervalo de $5 \mathrm{nT}$ e o resultado está mostrado na figura $7 \mathrm{~b}$. Observa-se, neste último caso, que
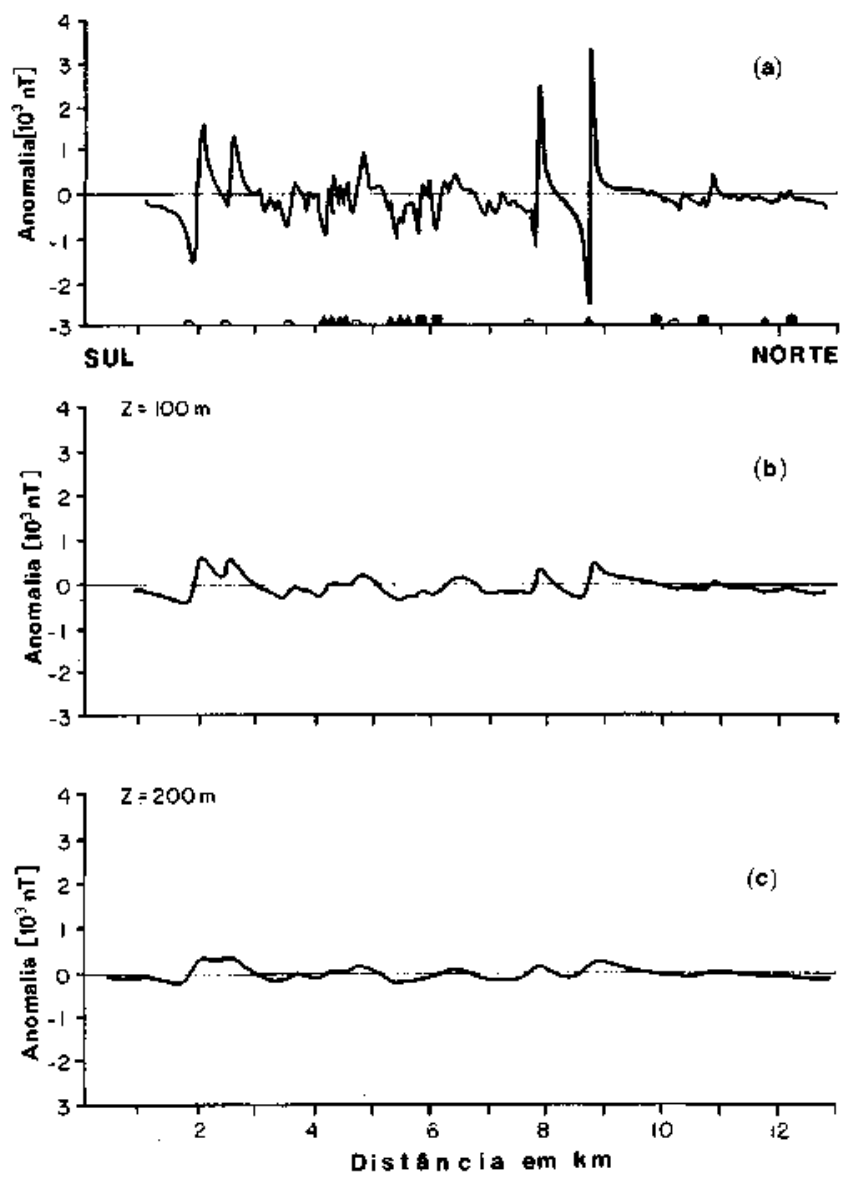

Figura 6-Resultados do processo de continuação para cima (a) dos dados terrestres, (b) para altura de $100 \mathrm{~m} \mathrm{e} \mathrm{(c)} 200 \mathrm{~m}$ acima da altitude média do terreno

Figure 6 - Upward continuation of (a) ground magnetometry, (b) at $100 \mathrm{~m}$ and (c) at $200 \mathrm{~m}$ above ground level

a diminuição do intervalo de contorno não ressalta qualquer anomalia magnética atribuível aos diques observados no campo. Na figura 8, são mostrados os perfis magnéticos resultantes: a. do processo de continuação para cima dos dados magnéticos terrestres para uma altura de $450 \mathrm{~m}$;

b. dos dados ao longo da linha de vôo (linha 560 - Folha SF.22Z-D-I-3) e coletados pela aeronave a $450 \mathrm{~m}$ com espaçamento médio de $100 \mathrm{~m}$ entre as leituras e

c. dos dados digitalizados do mapa de contorno da figura $\mathrm{Tb}$.

A discrepância nos valores no eixo vertical das anomalias no perfil (a) e perfis (b) e (c) deve-se ao processo de remoção do campo regional. Exceto por uma constante, os perfis (a) e (b) mostram boa concordância para anomalias de curto comprimento de onda. O perfil (c) mostra que o processo de elaboração dos mapas de contorno com resolução de $1 \mathrm{~km} \times 1 \mathrm{~km}$, definida a partir do espaçamento entre as linhas de vôo N-S, eliminou todas as anomalias associadas aos diques que ainda podem ser detectados pela aeromagnetometria a $450 \mathrm{~m}$ de altura. Concluise, desta análise, que os lineamentos magnéticos de direção NW nos mapas de contorno (Fig. 7a e Tb) não têm correlação direta com os diques mas devem refletir estruturas no embasamento que podem ou não corresponder a diques. Na figura $7 \mathrm{a}$, os lineamentos magnéticos que ali são mostrados têm compri-mento de onda de alguns quilômetros e, portanto, não podem ser gerados pelos diques que possuem apenas algumas dezenas de metros de largura.

Fontes das anomalias detectadas por aeromagnetometria Nas figuras 8a e 8b, observa-se que, a $450 \mathrm{~m}$ acima 

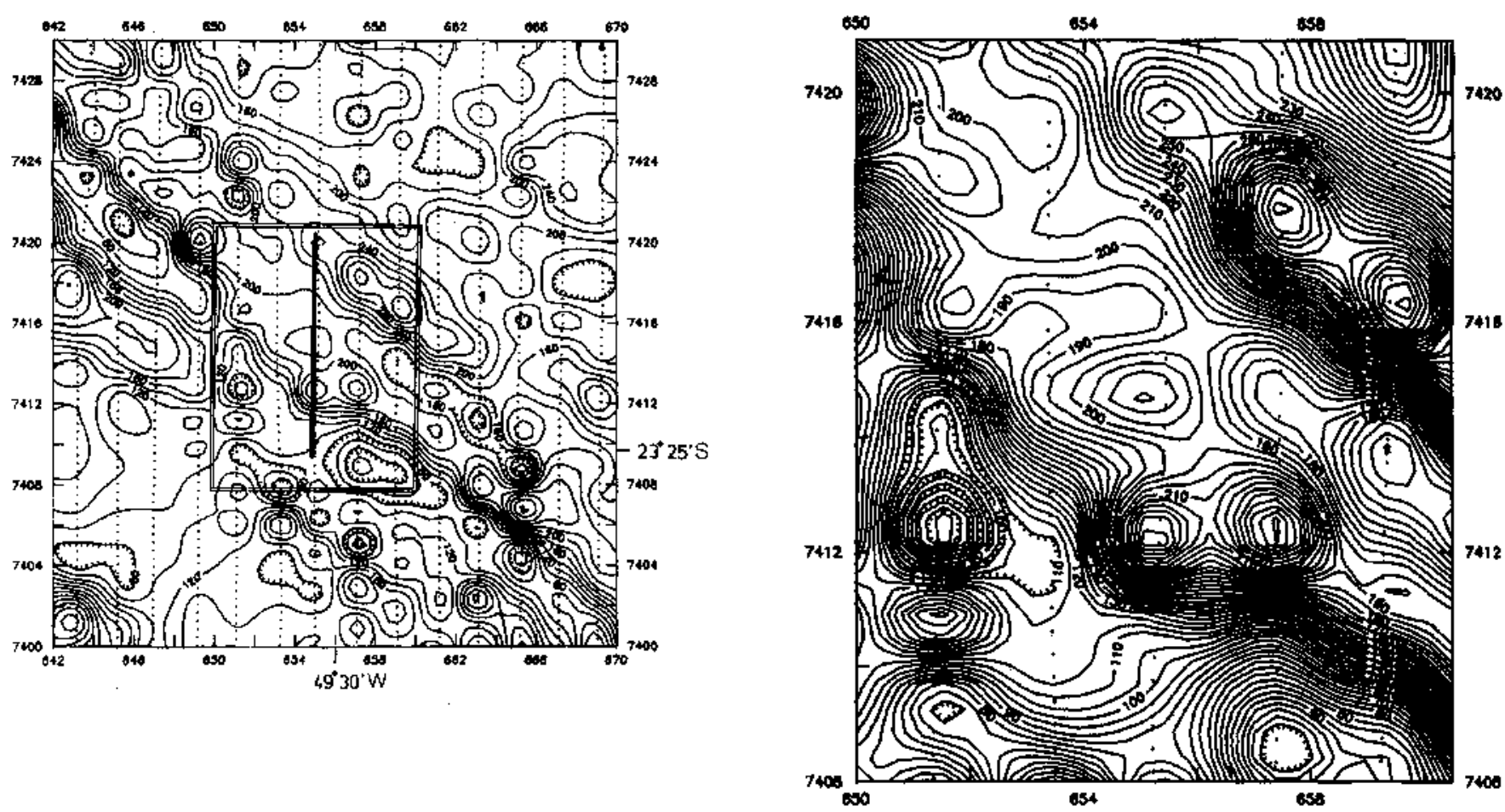

Figura 7-a. Mapa de contorno aeromagnético do projeto Botucatu obtido a partir da interpolação dos dados da linha de vôo (linha pontilhada) numa grade regular de $1 \mathrm{~km} \times 1 \mathrm{~km}$. Intervalo de contorno $20 \mathrm{nT}$. A linha vertical mais espessa corresponde à localização do perfil de magnetometria terrestre. O retângulo indica a área do mapa mostrado na figura $7 b$. b. Mapa de contorno aeromagnético da área de projeto estudo, indicado com um retângulo na figura $7 a$. Intervalo de contorno 5 nT Figure 7-a. Contour map of aeromagnetic survey named Botucatu project obtained from interpolation of the data along flight lines (dotted lines) in a regular grid of $1 \mathrm{~km} \times 1 \mathrm{~km}$. Contour interval $20 \mathrm{nT}$. The thick line is the location of the ground magnetometry profile. The rectangle is the area shown in figure $7 \mathrm{~b}$. b. Contour map of the rectangle area shown in figure 7a. Contour interval $5 \mathrm{nT}$
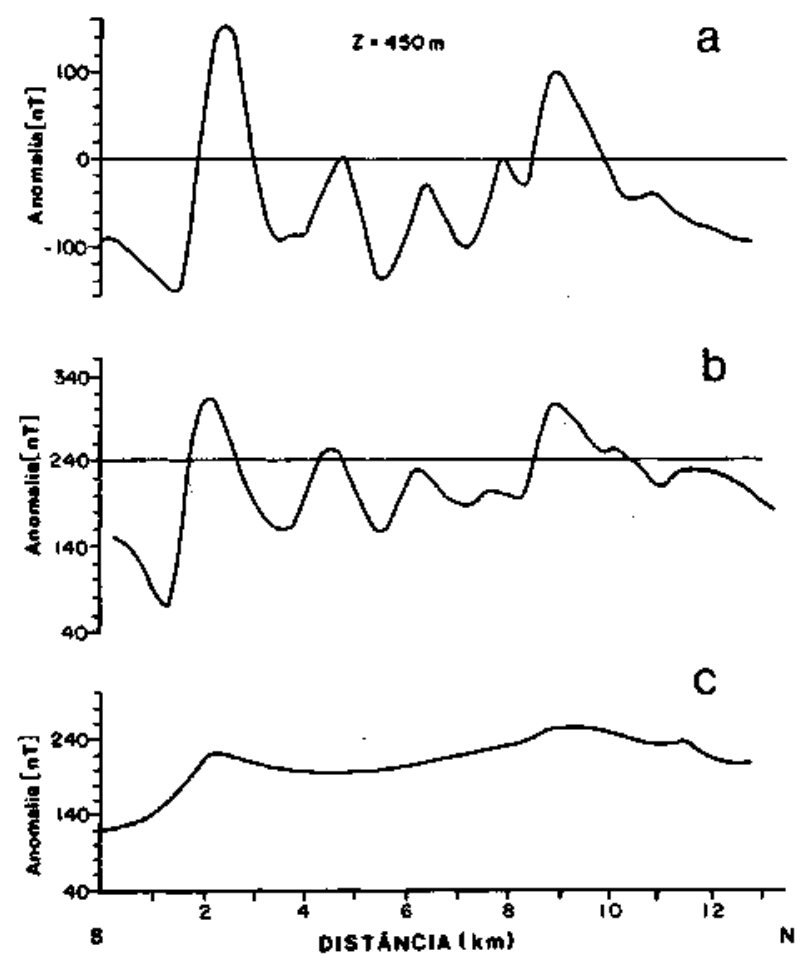

Figura 8 - Comparação entre a. dados magnéticos terrestres continuados a $450 \mathrm{~m}$ acima do terreno, b. dados coletados pelo aerolevantamento ao longo da linha de vôo e c. dados digitalizados do mapa de contorno da figura $7 a$

Figure 8 - Comparison between a. ground magnetometry upward continued to $450 \mathrm{~m}$ above ground level, $\mathbf{b}$. data collected by the aircraft and c. digitized data from contour map shown in figures $7 \mathrm{a}$ and $7 \mathrm{~b}$ do terreno, o magnetômetro ainda é capaz de detectar anomalias de comprimentos de onda de dois quilômetros e $200 \mathrm{nT}$ de amplitude pico a pico. O próximo passo é, portanto, inferir a fonte das anomalias detectadas naquela altitude. Com esta finalidade, foi determinada em laboratório a magnetização dos diques a fim de utilizá-la no cálculo do efeito magnético prod-zido por esses corpos, na superfície e na altura de $450 \mathrm{~m}$, e posteriormente comparar os resultados com os dados coletados no campo.

MAGNETIZAÇÃO DOS DIQUES Na tabela 1 são mostrados os valores de susceptibilidade magnética, intensidade e direção de magnetização remanescente natural dos diques amostrados ao longo do perfil de magnetometria terrestre (Fig. 2). Os procedimentos laboratoriais de medida da magnetização dos diques são aqueles descritos em Raposo \& Ernesto (1989). Observa-se que cinco dos oito diques amostrados possuem magnetização remanescente maior que a induzida, como mostrado pelo fator de Koenisberger (Q) que dá a razão entre a magnetização natural (MRN) e induzida (Susceptibilidade Magnética (k) x Intensidade do Campo Indutor). A mesma freqüência de diques na tabela 1 apresentam polaridade magnética reversa, ou seja, inclinação positiva.

CÁLCULO DIRETO DAS ANOMALIAS MAGNÉTICAS No perfil da figura 5 existe um conjunto de diques ( ${ }^{\text {os }} 1$ a 4$)$ e um dique isolado $\left(n^{\circ} 6\right)$ que foram amostrados e tiveram suas magnetizacões determinadas. Conhecia-se a largura aparente dos mesmos (Tab. 1) a partir de dados de campo. Utilizando os dados da tabela 1 , procedeu-se ao cálculo do efeito magnético destes diques na superficie e a uma altura de $450 \mathrm{~m}$ do topo dos diques. $\mathrm{O}$ cálculo foi efetuado utilizando o algoritmo proposto por Won \& Bevis (1987), modificado para levar em conta a magnetização remanescente. Os resultados estão mostrados nas figuras $9 \mathrm{a}$ e $9 \mathrm{~b}$. 
TABELA J-Dados de magnetização dos diques da região de Fartura. MRN. Intensidade da Magnetização Remanescente Natural, D. Declinação da MRN em graus, L Inclinação da MRN em graus, $k$. susceptibilidade magnética, $\boldsymbol{Q}$. razão de Koenisberger. * Enxame de Diques, somente um amostrado; + Dique ácido

Table 1 - Magnetization of dykes from Fartura region. MRN. Natural Remanent Magnetization Intensity, D. Declination of MRN in degrees, I. Inclination of MRN in degrees, k. magnetic susceptibility, Q. Koenisberger ratio, * Dykes Swarm (only one sampled); + Acid Dyke.

\begin{tabular}{|c|c|c|c|c|c|c|}
\hline $\begin{array}{c}\mathbf{N}^{*} \\
\mathrm{Dtg}_{\mathrm{H}}\end{array}$ & $\begin{array}{c}\text { Largure } \\
\text { Aparepte (in) }\end{array}$ & 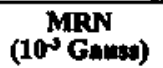 & $\mathbf{D}$ & I & $\underset{(\operatorname{cog} a)}{\mathbf{k}}$ & $\mathbf{Q}$ \\
\hline $\begin{array}{l}1 \\
2 \\
3 \\
4 \\
5 * \\
6 \\
7+ \\
8\end{array}$ & $\begin{array}{l}50 \\
50 \\
50 \\
50 \\
50 \\
75 \\
75 \\
20\end{array}$ & $\begin{array}{c}0,34 \\
2,30 \\
0,39 \\
4,34 \\
1,03 \\
13,89 \\
0,09 \\
0,85\end{array}$ & $\begin{array}{l}352 \\
171 \\
176 \\
348 \\
190 \\
34 \\
184 \\
352\end{array}$ & $\begin{array}{r}-36 \\
32 \\
43 \\
-40 \\
-2 \\
-56 \\
50 \\
-35\end{array}$ & $\begin{array}{l}0,0022 \\
0,0031 \\
0,0024 \\
0,0064 \\
0,0042 \\
0,0035 \\
0,0004 \\
0,0036\end{array}$ & $\begin{array}{c}0,66 \\
3,18 \\
0,68 \\
2,89 \\
1,05 \\
12,21 \\
0,89 \\
2,13\end{array}$ \\
\hline
\end{tabular}

As anomalias observadas na superfície sobre um grupo de diques ( ${ }^{\text {os }} 1$ a 4$)$, bem como sobre o dique $n^{\circ} 6$ são, quase que em sua totalidade, explicadas pela magnetização maior que a dos sedimentos. A uma altitude de $450 \mathrm{~m}$, é ainda possível
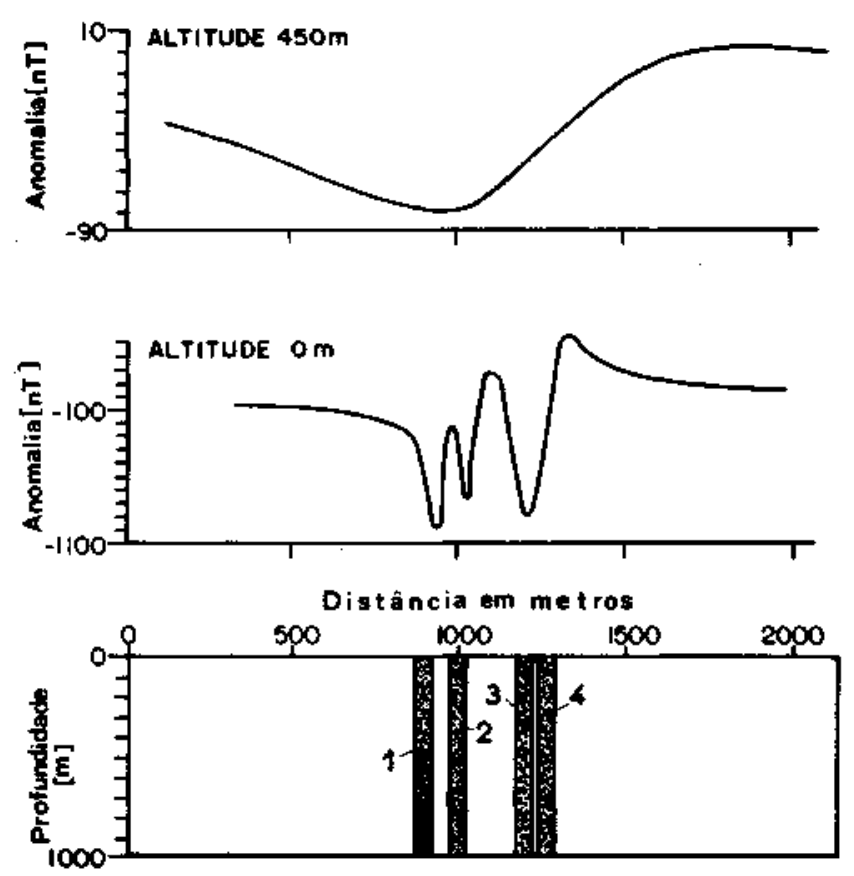

detectar anomalias causadas pelos diques. No entanto, no caso de um grupo de diques com largura menor que 20 m (Fig. 9a), observa-se uma única anomalia, ou seja, nesta altitude, tornase impossível discriminar a freqüência de ocorrência dos diques. No caso do dique $n^{\circ} 6$, é possível observar que, na superfície, a anomalia possui uma grande amplitude (6.000 nT pico a pico) e, a uma altitude de $450 \mathrm{~m}$, a amplitude decresce para $120 \mathrm{nT}$ pico a pico. Conclui-se desta análise que, a $450 \mathrm{~m}$ de altitude, somente grupos de diques e diques com alta magnetização podem ser detectados.

\section{DETECTABILIDADE MAGNÉTICA DE DIQUES POR}

AEROLEVANTAMENTOS Utilizando os dados de magnetização dos diques obtidos em laboratório foi construído um diagrama que estabelece um critério quantitativo de detectabilidade de diques. Os resultados estão resumidos na figura 10. O gráfico mostra, para duas alturas de vôo, 150 e $450 \mathrm{~m}$ acima do terreno, os valores esperados de amplitude da anomalia da componente total do campo sobre diques com diferentes magnetizações e larguras. Os valores de magnetização no eixo horizontal são expressos em termos de susceptibilidade magnética aparente (Fedi 1989) e real. A susceptibilidade aparente leva em conta a magnetização remanescente e é definida pela razão de Koenisberger $\mathrm{O}$ :

$$
\mathbf{Q}=\left|\mathbf{M}_{\gamma}\right| / \mathbf{M}_{\mathbf{l}} \mid
$$

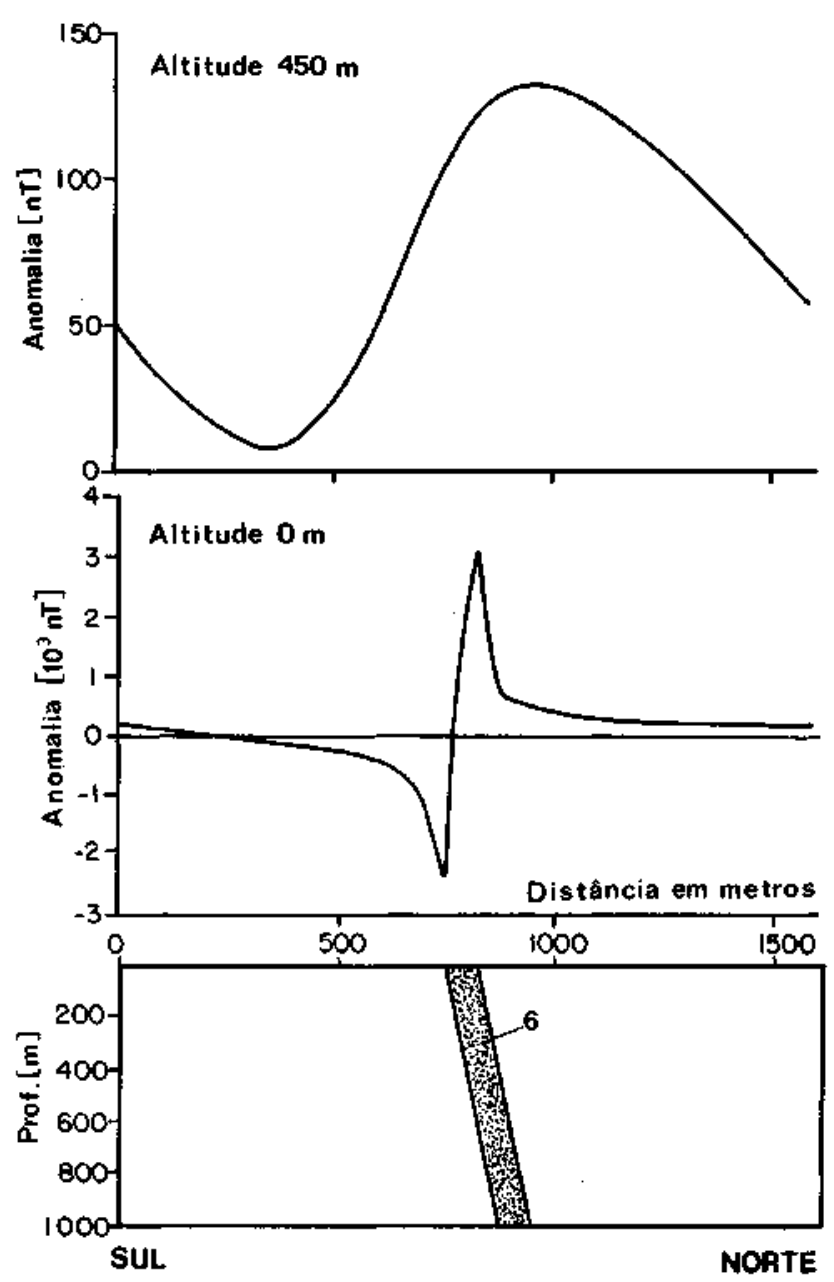

Figura 9 - Anomalias magnéticas calculadas na superficie e a 450 m acima da superficie para a. diques numerados como 1,2,3 e 4 na figura 5; b. dique fortemente magnetizado $n^{\circ} 6$ na figura 5. Os valores de magnetização dos diques são aqueles mostrados na tabelai

Figure 9 - Calculated magnetic anomalies on the ground and at $450 \mathrm{~m}$ above ground level for a. dykes numbered as 1.2,3 and 4 in figure 5; b. highly magnetized dyke numbered as 6 in figure 5. Magnetic properties of these dykes are those shown in table 1 


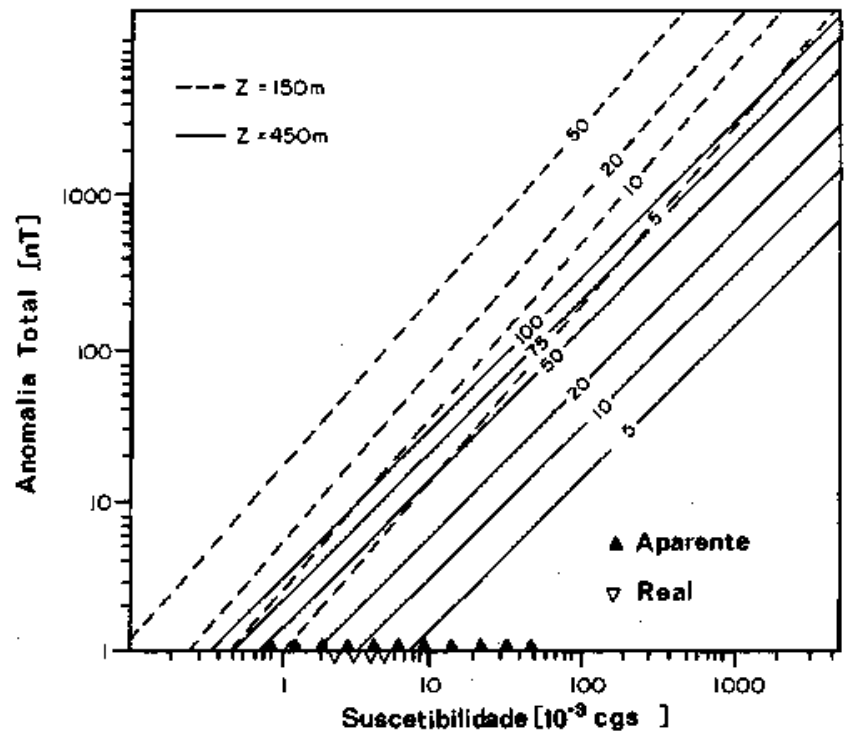

Figura 10- Diagrama quantitativo de deteclabilidade magnética de diques por aerolevantamentos. $\boldsymbol{Z}$ é a altitude da linha de vôo e o número em cada reta indica a largura do dique em metros

Figure 10 - Quantitative criteria of dyke detectability for different flight heights $Z$. The number in each curve is the dyke thickness in meters

onde:

|M,| é a magnetização remanescente

$\mid \mathrm{M}$, é a magnetização induzida

$\mathrm{IH}|=\mathrm{k}| \mathrm{T} \mid$

onde:

$\mathrm{k}=$ susceptibilidade magnética

$|\mathrm{T}|=$ Intensidade do campo indutor externo

$\mathrm{O}$ valor absoluto da intensidade de magnetização $|\mathrm{J}|$ é:

$|\mathrm{J}|=\left|\mathbf{M}_{\mathbf{l}}\right|+\left|\mathrm{M}_{\mathrm{T}}\right|=\mathbf{k}|\mathbf{T}|+\left|\mathbf{M}_{\mathrm{r}}\right|=\mathbf{k}_{\mathrm{c}}\left|\mathrm{T}^{\prime}\right|$

\section{$k_{r}^{2}\left|T^{p}\right|^{2}=\left.k^{2}\left|T^{2}+\right| M_{r}\right|^{2}+2 k\left|H_{\mid}\right| M_{r} \mid\left[\cos L_{t} \cos I_{m} \cos \left(D_{t}-D_{m}\right)+\right.$ $+\operatorname{sen} L \mathrm{~L}$

onde $I_{t}, D_{t}$, e $I_{m} D_{m}$ são as inclinações e declinações dos vetores campo geomagnético indutor e magnetização remanescente, respectivamente. Dividindo a expressão (5) por $\left|\mathrm{T}^{\prime}\right|^{2}$

$$
\begin{aligned}
k c= & k\left\{1+Q^{2}+2 Q\left[\cos L_{1} \cos I_{m} \cos \left(D_{1}-D_{j}\right)+\right.\right. \\
& \left.\left.+\operatorname{sen} l_{1} \operatorname{sen} I_{m}\right]\right\}^{k}
\end{aligned}
$$

$\mathrm{Na}$ área deste estudo, $\mathrm{T}=23.000 \mathrm{nT}, \mathrm{I},=-23^{\circ}$ e $\mathrm{D}_{\mathrm{t}},=-17^{\circ}$, $\mathrm{I}_{\mathrm{m}}$ e $\mathrm{D}_{\mathrm{m}}$ são listados na tabela 1 .

De acordo com ps valores de intensidade e direção da magnetização dos diques resumidos na tabela 1 , a susceptibilidade aparente varia de $10^{-3}$ a $5 \times 10^{-2}$ cgs. Considerando que a anomalia mínima detectável, definida pelo erro nas correções da variação diurna do campo, seja de $10 \mathrm{nT}$, diques com largura de $10 \mathrm{~m}$ só serão detectados a $450 \mathrm{~m}$ de altura de vôo se possuírem forte magnetização, ou seja, susceptibilidade aparente maior que $5 \times 10^{-2}$ cgs. O valor médio de magnetização dos diques da região estudada está mais próximo de $10^{-2} \mathrm{cgs}$. Neste caso, a $450 \mathrm{~m}$ de altura, somente diques com largura superior a $50 \mathrm{~m}$ serão detectados. Para uma altura de vôo de $150 \mathrm{~m}$, diques com largura maior que $10 \mathrm{~m}$ seriam detectados desde que apresentassem susceptibilidade aparente próxima de $10^{-2}$ cgs. Diques com largura menor que $10 \mathrm{~m}$, mesmo para baixas altitudes de vôo, como $150 \mathrm{~m}$, dificilmente serão detectados.

CONTINUIDADE DOS DIQUES PARA O INTERIOR DA BACIA Os resultados deste estudo mostram que a inferência de continuidade dos diques do Arco de Ponta Grossa para o interior da Bacia do Paraná, baseada apenas em mapas aeromagnéticos de contorno, é problemática, uma vez que a baixa resolução dos mapas não permite afirmar se os diques ocorrem ou não associados aos lineamentos magnéticos regionais observados na parte leste da bacia.

Com o objetivo de tentar esclarecer esta questão, dois perfis magnetométricos terrestres adicionais foram implantados no interior da Bacia do Paraná, onde os diques não afloram, mas onde são observados lineamentos nos mapas aeromagnéticos (Ferreira 1982a,b). A localização dos perfis é mostrada na figura 11.

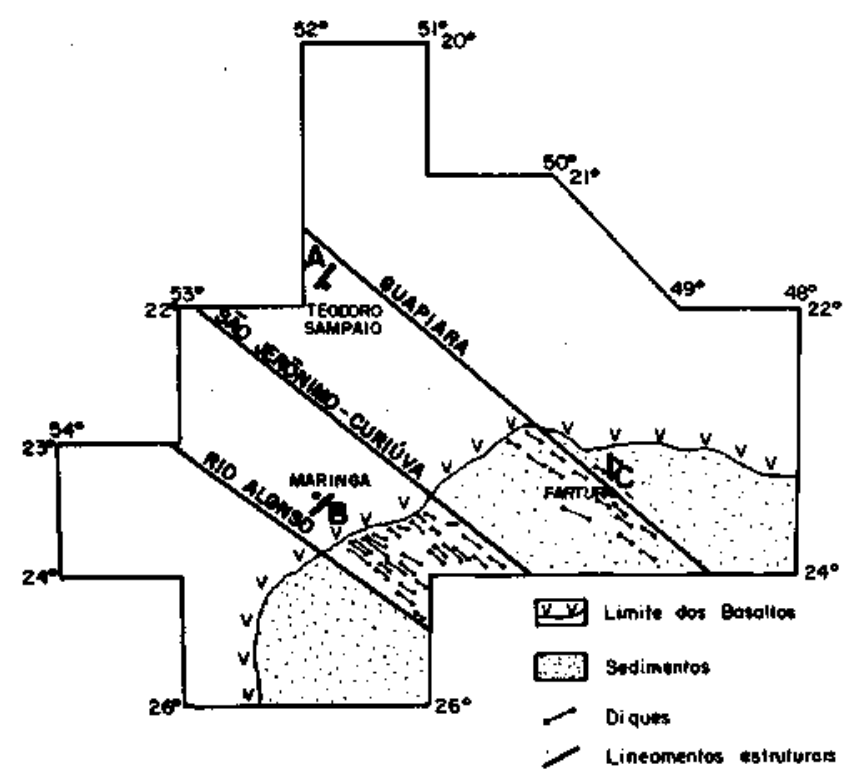

Figura 11 - Mapa de localização dos perfis magnetométricos terrestres no interior da Bacia do Paraná

Figure 11 - Location of ground magnetometry profiles within the Paraná Basin

O perfil A situa-se na localidade de Teodoro Sampaio (SP), onde os basaltos do Formação Serra Geral são cobertos pelos arenitos da Formação Caiuá (Grupo Bauru). O perfil B situa-se na cidade de Maringá, onde afloram apenas basaltos da Formação Serra Geral, cobertos por espessa camada de solo.

Os resultados dos dois levantamentos estão mostrados na figura 12. Os valores das anomalias da componente total do campo estão corrigidos das variações diurnas, tendo sido também removido o campo regional. $\mathrm{O}$ espaçamento entre as leituras variou de 12,5 a $25 \mathrm{~m}$.

$\mathrm{O}$ perfil $\mathrm{B}$, na região de Maringá, mostra anomalias magnéticas de curto comprimento de onda que podem ser atribuídas à ocorrência de diques. No entanto, existe outra possibilidade que deve ser considerada, a existência de falhas nos derrames. Na figura 13, são mostradas as anomalias magnéticas calculadas como se o topo dos derrames basáticos estivesse falhado, logo abaixo de uma camada de solo de cerca de $5 \mathrm{~m}$ de largura. Esta modelagem mostra ser possível que algumas das anomalias de curto comprimento de onda no perfil A da figura 12 sejam causadas por falhas e/ou fraturas nos derrames da Formação Serra Geral, resultantes do processo de resfriamento das 


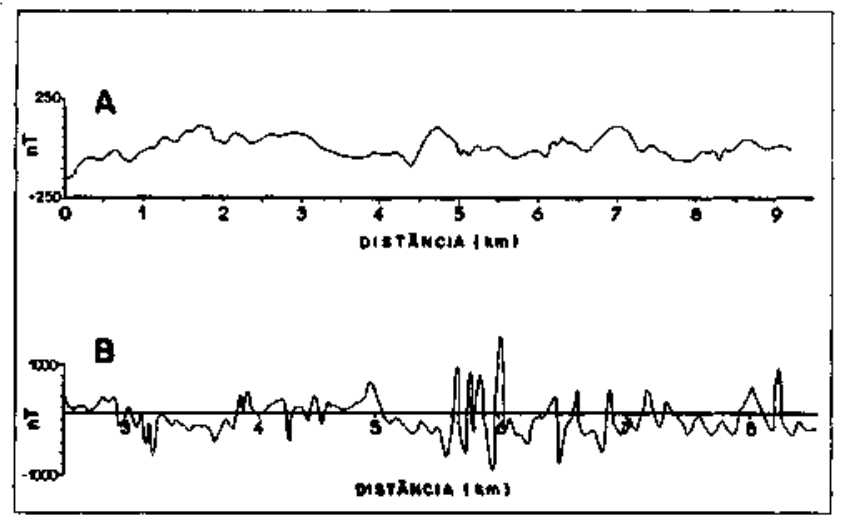

Figura 12-Anomalias da componente total do campo obtidas nos levantamentos magnetométricos terrestres $\boldsymbol{A}$ e $\boldsymbol{B}$, mostrados na figura 11

Figure 12 - Total component magnetic anomalies of ground magnetometry profiles $\mathrm{A}$ and $\mathrm{B}$ shown in figure 11

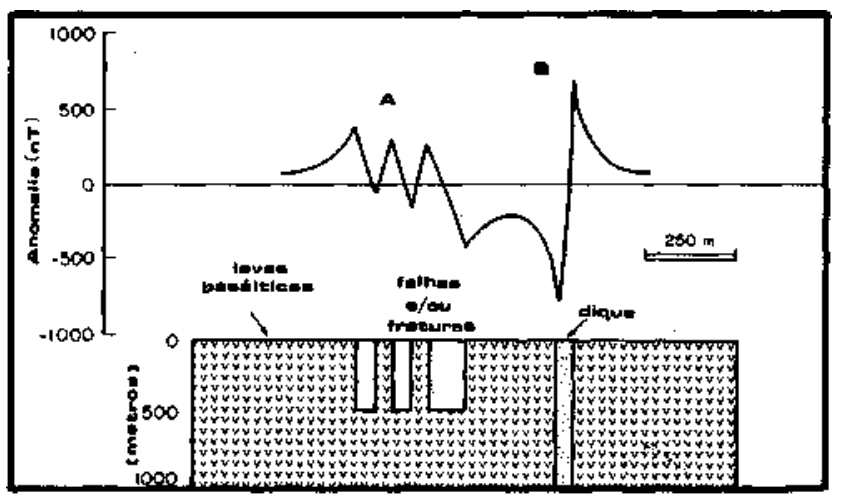

Figura 13 - Cálculo do efeito magnético induzido em fraturas no topo dos derrames de lavas (A), comparado com a anomalia magnética típica produzida por um dique (B). A espessura de solo sobre a camada de basalto é de $5 \mathrm{~m}$, o rejeito das falhas verticais de $500 \mathrm{~m}$ e susceptibilidade do basalto de 0,01 cgs. Campo indutor $23.000 n T$, inclinação $-23^{\circ}$, declinação $-17^{\circ}$. A largura do dique é de $20 \mathrm{~m}$ e o topo situado a $5 \mathrm{~m}$ abaixo da superficie e a magnetização $0,03 \mathrm{cgs}$

Figure 13 - Magnetic anomalies associated with faults or fractures at the top of lava flows (A) compared with magnetic anomaly of a magnetized dyke (B). The thickness of soil on top of the basaltic layer is 5 meters, throw of vertical faults is $500 \mathrm{~m}$ and the magnetic susceptibility of basalt is $0.01 \mathrm{cgs}$. External field $23,000 \mathrm{nT}$, inclination $-23^{\circ}$. Dyke thickness is $20 \mathrm{~m}$ with top situated at $5 \mathrm{~m}$ below the surface and magnetic susceptibility of $0.03 \mathrm{cgs}$

lavas ou, então, devido a um evento tectônico posterior ao resfriamento.

As anomalias magnéticas de amplitude pico a pico maior que $1.000 \mathrm{nT}$, como aquelas observadas entre os km 5,5 e 6,0 na figura 12 , dificilmente poderiam ser causadas por fraturas no topo da camada basáltica associadas a processos de resfriamento. Considerando o limite superior de $0,01 \mathrm{cgs}$ para a susceptibilidade magnética aparente das lavas (Ferreira 1982a), o rejeito das falhas no topo da camada basáltica deveria ser de $500 \mathrm{~m}$ para explicar as anomalias de amplitude pico a pico de $500 \mathrm{nT}$. No entanto, não existem evidências de que nesta região ocorram falhas com este rejeito. Desta forma, as anomalias com amplitude maior que $500 \mathrm{nT}$ devem estar associadas a diques com magnetização maior que a das lavas. Observa-se que, em geral, os diques de diabásio apresentam uma magnetização maior que as lavas, tanto a susceptibilidade magnética como a magnetização remanescente natural. Esta observação é explicada pela diferença entre a granulometria das rochas dos diques e das lavas, controlada pela história de resfriamento dos dois litotipos.

Se as anomalias magnéticas de grande amplitude na região de Maringá são produzidas por diques, então estes devem estar bem próximos da superfície, embora não aflorantes. Esta conclusão é inferida a partir dos resultados do processo de continuação para cima dos dados magnéticos terrestres da região de Fartura. A anomalia magnética na altura de $100 \mathrm{~m}$ acima da fonte é cerca de sete vezes menor que a amplitude da anomalia medida na superfície. A largura de basaltos na região de Maringá é de aproximadamente $800 \mathrm{~m}$, conforme dados de poço na cidade próxima de Arapongas (Poço 2-AP-1-PR, Paulipetro 1982). Portanto, as anomalias de cerca de $2.000 \mathrm{nT}$ de amplitude indicam que os diques, além de estarem próximos da superfície, devem necessariamente cortar a espessa seqüência basáltica.

No perfil A, situado nas proximidades do eixo NE da bacia do Paraná, as anomalias magnéticas apresentam-se bastante atenuadas. No entanto, ainda são observadas algumas anomalias que poderiam ser atribuídas a diques em profundidade,

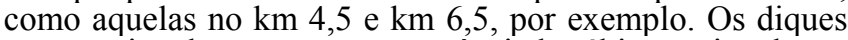
nesta região devem cortar a seqüência basáltica, estimada em cerca de $1.700 \mathrm{~m}$. No entanto, o sinal magnético está atenuado, uma vez que o dique acha-se encoberto com pelo menos $100 \mathrm{~m}$ de arenitos da Formação Caiuá (Poço 2-CB-1-SP, Paulipetro 1982). Desta forma, na região central da Bacia do Paraná, a detecção magnética de diques, mesmo por levantamentos terrestres, torna-se bastante difícil.

DISCUSSÃO A figura 14 resume uma possível relação estratigráfica e estrutural dos diques nas regiões A, B e C. Os resultados do presente trabalho sugerem que, se os diques aflorantes na região do Arco de Ponta Grossa (C) continuam para o interior da bacia, estes devem necessariamente cortar a espessa seqüência de derrames vulcânicos (A e B). Outros trabalhos de magnetometria terrestre deveriam ser conduzidos no interior da bacia do Paraná, fora da região de influência do Arco de Ponta Grossa, a fim de verificar se diques ocorrem aleatoriamente em toda a extensão da bacia afetada pelo vulcanismo da Formação Serra Geral ou se houve um condicionamento tectônico regional na colocação destes corpos.

A hipótese de que os diques cortam a espessa seqüência vulcânica implica que o tectonismo e o magmatismo que os originaram devem ter ocorrido na fase final ou são posteriores ao derrame. Esta observação concorda com os resultados de estudos geológicos/geoquímicos (Piccirillo et al. 1988b) e paleomagnéticos (Ernesto \& Pacca 1988) de derrames de toda Bacia do Paraná e diques do Arco de Ponta Grossa. Estes estudos atribuíram uma fase mais tardia ao evento intrusive dos diques e sills dentro de um quadro de migração do vulcanismo de sul para norte e de oeste para leste, precedendo a ruptura do supercontinente Gondwana e a formação do Atlântico Sul.

CONCLUSÕES Os resultados obtidos no estudo integrado de magnetometria terrestre, aérea e magnetização de rochas mostram que:

a. os mapas de contorno em escala 1:50.000 e 1:100.000 da região do Arco de Ponta Grossa e do interior da bacia do Paraná não possuem resolução suficiente para mostrar as anomalias produzidas pelos diques. Este resultado pode ser estendido a mapas de contorno de outros aerolevantamentos efetuados no Brasil. A grade de interpelação que gera as curvas de contorno ou a re-amostragem dos dados em intervalos maiores que $250 \mathrm{~m}$ antes de gerar a grade regular, elimina anomalias com comprimento de onda menor que $1 \mathrm{~km}$. Os lineamentos magnéticos observados nestes mapas devem refletir principalmente feições estruturais no embasamento cristalino preenchidas ou não por diques;

b. os dados de anomalias magnéticas ao longo da linha de vôo com espaçamento médio de $100 \mathrm{~m}$ entre as leituras e a uma 

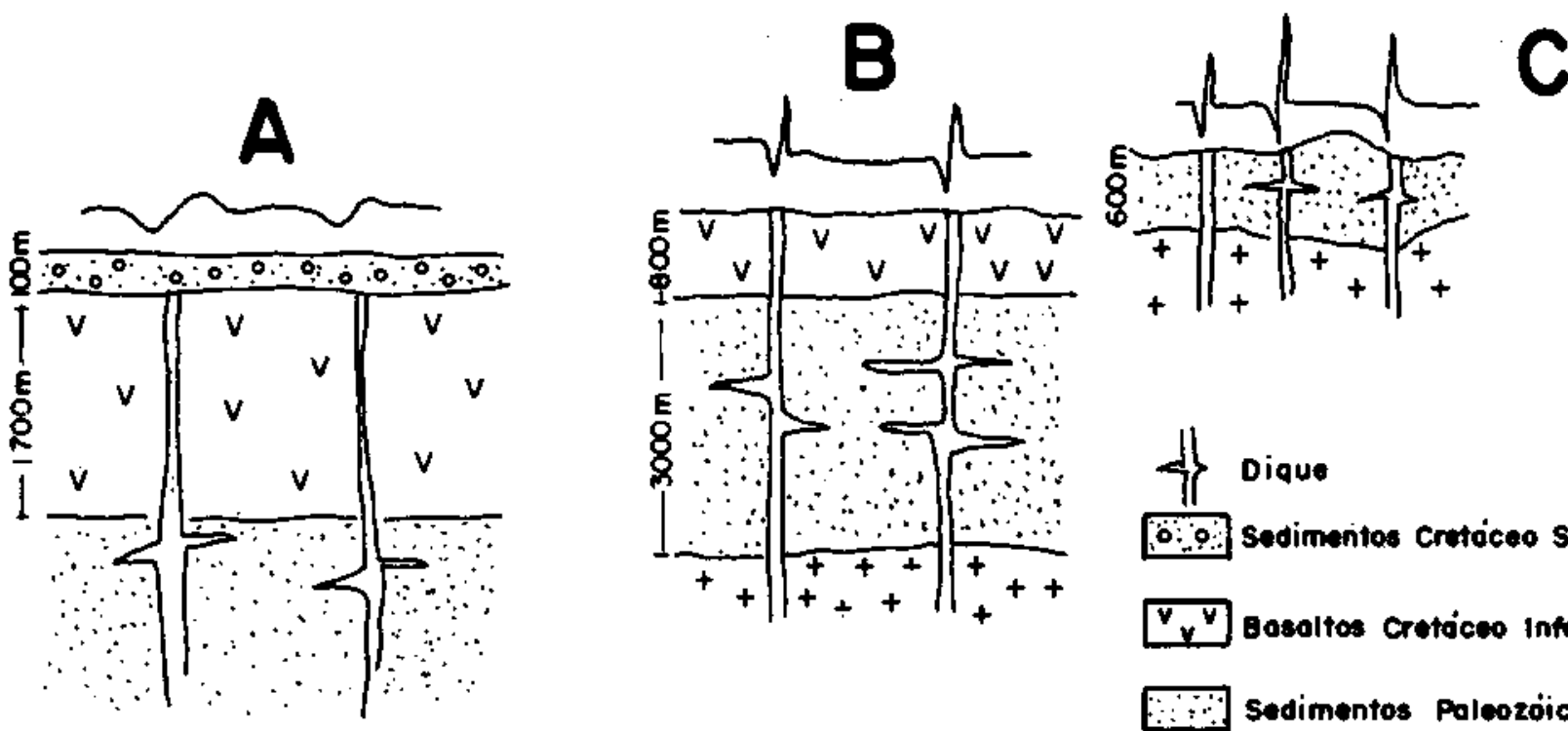

6:0] Sedimentes Cratoceo superior

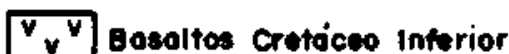

Sedimentos Poleozóicos

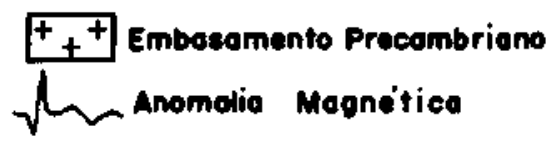

Figura 14 - Diagrama esquemático da possível relação estrutural dos diques com os sedimentos paleozóicos (C), diques e derrames vulcânicos da Formação Serra Geral (B) e diques, vulcânicas e sedimentos do Cretáceo Superior (A) Figure 14 - Summary of structural relation between dykes and Paleozoic sediments (C), dykes and basaltic flows (B) and dykes, basaltic flows and Upper Cretaceous sediments (A)

altura de $450 \mathrm{~m}$ acima do terreno somente mostram anomalias devidas a um grupo de diques ou dique com forte magnetização (> $4.000 \mathrm{nT}$ na superfície). Portanto, a partir dos dados ao longo da linha de vốo em aerolevantamentos de baixa resolução não é possível determinar a freqüência de ocorrência de diques; c. da mesma forma que existem diques não aflorantes que são detectados por levantamentos magnéticos, ocorrem diques cuja magnetização é bastante baixa e não produzem anomalias magnéticas detectáveis. Isto reforça a necessidade de procurar integrar dados geológicos e sensoriamento remoto com dados de aeromagnetometria e magnetometria terrestre em estudos e mapeamento destes corpos;

d. estudos magnetométricos de detalhe definidos a partir das principais características magnéticas regionais resultantes de aerolevantamentos na Bacia do Paraná contribuiriam para o refinamento do conhecimento do seu arcabouço estrutural, bem como no entendimento da evolução do vulcanismo mesozóico, aqui exemplificados pela utilização do método na inferência da relação estrutural entre as lavas e os diques no interior da bacia, onde a observação direta não é possível.

Agradecimentos Este trabalho foi inspirado nas constantes perguntas provocativas formuladas por Enzo Piccirillo sobre o vulcanismo da Bacia do Paraná, a ele são dirigidos os nossos agradecimentos. $\mathrm{O}$ auxílio financeiro foi concedido pela FAPESP (proc. 88/4293) e PADCT/FDSfEP (proc. 43.89.0125.00). Agradecemos também a um revisor anônimo pelas sugestões referentes à magnetometria.

\section{REFERÊNCIAS BIBLIOGRÁFICAS}

BARANOV, W. 1975. Potential fields and their transformations in Applied Geophysics. Berlim, Geoexploration Monographs GebruederBomtraeger. $121 \mathrm{p}$. (Series 1, ${ }^{\circ} 2$ )

DNPM 1984 Inventário dos Levantamentos Aerogeofisicos Executados pelo Departamento Nacional da Produção Mineral. Brasília, DNPM. 134 p. (Série Geologia 25, Seção Geofísica 3).

ERNESTO, M. \& PACCA, I.I.G. 1988 Paleomagnetism of the Paraná basin flood volcanics, southern Brazil. In: PICCIRILLO, E.M. \& MELFI, A.J. ed. The Mesozoic flood volcanism of the Parana basin: Petrogenetic and geophysical aspects. São Paulo, LAG/USP. p. 229-255.

FEDI, M. 1989. On the interpretation of magnetic anomalies for strong remanent magnetization. Pageoph., 130(4):721-733.

FERREIRA, F.J.F. 1982a. Integração de Dados Aeromagnéticos e Geoló-

gicos: Configuração e Evolução Tectônica do Arco de Ponta Grossa. São Paulo. 169 p. (Dissertação de Mestrado, IG-USP).

FERREIRA, F.J.F. 1982b. Alinhamentos estruturais magnéticos da região centro-oriental da bacia do Paraná e seu significado tectônico. In: Geologia da Bacia do Paraná. São Paulo, IPT. p. 143-166. (Publ. Especial 12).

FÚLFARO, V.J. \& SUGUIO, K. 1967. Campos de diques de diabásio da Bacia do Paraná. Boi. Soe. Bros. Geol, 16(2):23-37.

FÚLFARO, V.J. \& SUGUIO, K. 1974. Geologia da região de Fartura SP. In: CONOR. BRAS. GEOL., 28. Porto Alegre, 1974. Anais... Porto Alegre, SBG. v. 4, p. 173-180.
FÚLFARO, V.J.; SAAD, A.R.; SANTOS.M.V.; VIANNA.R.B. 1982. Compartimentacão e evolução tectônica da Bacia do Paraná. Rev. Bras. Geoc., 12:590-611.

KANASEVICH, E.R. 1981. Time Sequence Analysis in Geophysics. Edmonton, University of Alberta Press. $480 \mathrm{p}$.

PAULIPETRO. 1982. Geologia da Bacia do Paraná: Reavaliação das Potencialidades e Prospectividade em Hidrocarbonetos. São Paulo, Consórcio CESP/IPT. $198 \mathrm{p}$

PICCIRILLO, E.M.; COMIN-CHIARAMONTI, P.; MELFI, A.J.; STOLFA, D.; BELLIENI.G.; MARQUES.L.S.; NARDY, A.J.R.; PINESE, J.P.P.; RAPOSO, M.I.B.; ROISEMBERG, A. 1988a. Petrogenetic aspects of continental flood basalt-rhyolite suites from the Paraná basin (Brazil). In: PICCIRILLO, E.M. \& MELFI, A.J. eds. The Mesozoic Flood Volcanism of the Parana Basin: Petrogenetic and Geophysical Aspects. São Paulo, IAG-USP. p. 107-156.

PICCIRILLO, E.M.; BELLIENI, G.; COMIN-CHIARAMONTI, P.; ERNESTO, M. MELFI, A J. PACCA, II.G. USSAMI, N. 1988b. Significance of the Paraná flood volcanism in the disruption of the Western Gondwanaland, In: PICCIRILLO, E.M. \& MELFI, A.J. eds. The Mesozoic Flood Volcanism of the Paraná Basin: Petrogenetic and Geophysical Aspects. São Paulo, LM3-USP. p. 285-295.

RAPOSO, M.I.B. \& ERNESTO, M. 1989. Rochas intrusivas básicas do Arco de Ponta Grossa: resultados paleomagnéticos preliminares. Rev. Bras. Geoc.,19(3):393-400. 
SCHWARZ, E.J.; HOOD, P.J.; TESKEY, DJ. 1987. Magnetic expression of Canadian diabase dykes and downward modelling. In: HALLS, H.C. \& FAHRIG, W.F. Mafic Dyke Swarms. 34 , St. John's, Newfoundland, Geological Association of Canada, p. 153-162. (Special Paper).

WON, IJ. \& BEVIS, M. 1987. Computing the gravitational and magnetic anomalies due to a polygon: algorithms and Fortran subroutines. Geophysics, 52(2):232-238.
ZAINE, M.F. 1980. Uma Barreira Geográfica no Paleozóico Superior na Região de Fartura, SP. São Paulo. 109 p. (Dissertação de Mestrado, IG-USP).

MANUSCRITO A701

Recebido em 8 de abril de 1991 Revisão do autor em 30 de setembro de 1991 Revisão aceita em 8 de novembro de 1991 